\title{
DIETARY TREATMENT OF HYPERTENSION. III. THE EFFECT OF PROTEIN ON APPETITE AND WEIGHT
}

\author{
BY VINCENT P. DOLE, LEWIS K. DAHL, IRVING L. SCHWARTZ,1 GEORGE C. \\ COTZIAS, ${ }^{2}$ JØRN H. THAYSEN, AND CECILIA HARRIS
}

(From the Hospital of The Rockefeller Institute for Medical Research, New York, N. Y.)

(Submitted for publication October 10, 1952; accepted December 2, 1952)

In an earlier study (1) it was observed that patients rapidly lost weight following a change in diet from a conventional pattern to the rice-fruit diet of Kempner. Although the imbalance was but temporary, as shown by the approach to stable weight and nitrogen balance during the next four months, the weight remained at the lower level. During the period of rapid weight loss, the patients took a reduced number of calories as compared to their previous consumption. However, as the weight approached stability, the intake of calories rose to the neighborhood of the control values, despite the fact that the patients by this time were heartily bored with the menu. These observations and the finding that basal metabolic rates remained approximately constant, suggested that the daily expenditure of calories remained constant, but that the metabolic transition somehow required the oxidation of a certain bulk of tissue. It seemed of interest to plan further studies to isolate the dietary factor responsible for the transition, and to assess its importance in the therapy of hypertension.

In the subsequent study (2), which was directed mainly to the role of sodium, it was found that extreme changes in the ration of sodium had no important effect on the appetite or weight. Again in this study, the patients lost weight when given the basal diet despite the fact that all but one received a supplement of salt (10 gm. per day). The one patient who received no supplement exhibited a loss of weight which was indistinguishable from the others. It was surmised that the restriction of dietary protein to about $35 \mathrm{gm}$. per day, which appeared as an incidental restriction when dietary sodium was limited to $4 \mathrm{mEq}$. per day,

\footnotetext{
1 Research Fellow of the American Heart Association; supported in part by the Rosenstock Memorial Foundation.

2 Fellow of the American Cancer Society as recommended by the Committee on Growth of the National Research Council.
}

was the factor that caused the reductions in appetite and weight.

In the present study this hypothesis has been given a systematic test. Essentially the same basal diet has been employed, with the addition of a salt-free milk product which permitted large variations in the intake of protein while the ration of sodium was held constant. The results support the hypothesis that a regulation of dietary protein may determine appetite and weight. These effects were clearly separable from the therapeutic action of limiting sodium, since the restriction of protein had no effect on the mean blood pressure at either a high or low intake of sodium, and an antecedent loss of weight did not condition the subsequent response to restriction of sodium.

\section{PROCEDURE}

Six patients with uncomplicated hypertension served as subjects for the present study (Table I). A careful history and a complete physical examination was recorded for each patient. Signs of cardiovascular disease, in addition to hypertension, were limited to enlargement of the heart and to grade I to II changes in the fundi. Patients with cardiac failure, history or neurological evidence of central nervous system disease, or with kidney disease, were not taken for the study. After the patients were admitted to the metabolic ward, the following diagnostic tests were done: urinalysis, urea clearance, intravenous pyelogram, complete blood counts, plasma protein concentration, serology (Kolmer and Mazzini tests), electrocardiogram, X-ray of chest and the benzodioxane test of Goldenberg and his associates (3). The tests confirmed the absence of complicating disease. During the course of the study several tests were repeated at intervals of one to four weeks: urinalysis, urea clearance, plasma protein concentration, electrocardiogram, and X-ray of chest; the results accorded with those on admission.

All of the food during the six months of observation was supplied in weighed portions from a diet kitchen, any surplus left unconsumed being reweighed and subtracted. With the aid of standard tables $(4,5,6)$ the daily consumption of protein, carbohydrate, fat, total calories and sodium were computed. The basal diet was similar to the one used in the preceding study (2); it contained approximately $4 \pm 1 \mathrm{mEq}$. of sodium and $35 \pm$ 
TABLE I

Clinical data

\begin{tabular}{|c|c|c|c|c|c|}
\hline Patient & $\begin{array}{l}\text { R.I.H. } \\
\text { No. }\end{array}$ & Age & Sex & $\begin{array}{c}\text { Known } \\
\text { duration } \\
\text { of hyper- } \\
\text { tension }\end{array}$ & $\frac{\begin{array}{c}\text { Ratio } \\
\text { Initial wt. }\end{array}}{\text { Normal wt. }}$ \\
\hline & & years & & years & \\
\hline $\begin{array}{l}\text { A } \\
\text { B } \\
\text { C } \\
\text { D } \\
\mathbf{E} \\
\mathbf{F}\end{array}$ & $\begin{array}{l}12596 \\
12549 \\
12575 \\
12564 \\
12566 \\
12582\end{array}$ & $\begin{array}{l}36 \\
32 \\
48 \\
36 \\
45 \\
24\end{array}$ & $\begin{array}{l}F \\
F \\
M \\
M \\
M \\
F\end{array}$ & $\begin{array}{c}2 \\
8 \\
21 \\
4 \\
4 \\
0.3\end{array}$ & $\begin{array}{l}0.88 \\
1.00 \\
0.86 \\
1.16 \\
1.20 \\
1.06\end{array}$ \\
\hline
\end{tabular}

* "Normal weight" for each patient was calculated from normal values which had been derived from life insurance statistics (13).

$5 \mathrm{gm}$. protein per day. The different categories of food supplied calories in the approximate proportions: protein 5 per cent, carbohydrate 70 per cent, fat 25 per cent. When an increase in the intake of sodium was desired,
$10 \mathrm{gm} . \mathrm{NaCl}$ per day were given in gelatin capsules. The ration of protein was increased above the level of the basal diet by addition of a supplement; ${ }^{3}$ it was reduced by substituting for the basal diet one of minimal protein content ( $8 \mathrm{gm}$. per day). Throughout the entire study, including the periods of extreme restriction of protein, an unlimited supply of carbohydrate and fat was offered to each patient; in this way the total number of calories taken each day remained under the control of the patient's appetite.

In the first period, which was of some 6 to 7 weeks duration, the intake of sodium was held at $175 \mathrm{mEq}$. per day by the addition of salt in gelatin capsules, and the intake of protein, around $1.5 \mathrm{gm}$. per $\mathrm{kg}$. day. During the second period, again of 6 to 7 weeks duration, the intake of sodium was dropped to $4 \mathrm{mEq}$. per day without other changes in the regimen. In the third period, 5 to

8 "Lesofac" (Wyeth, Inc.) : 50 per cent milk proteins, 39 per cent carbohydrate, 1 per cent fat, 0.02 per cent sodium.
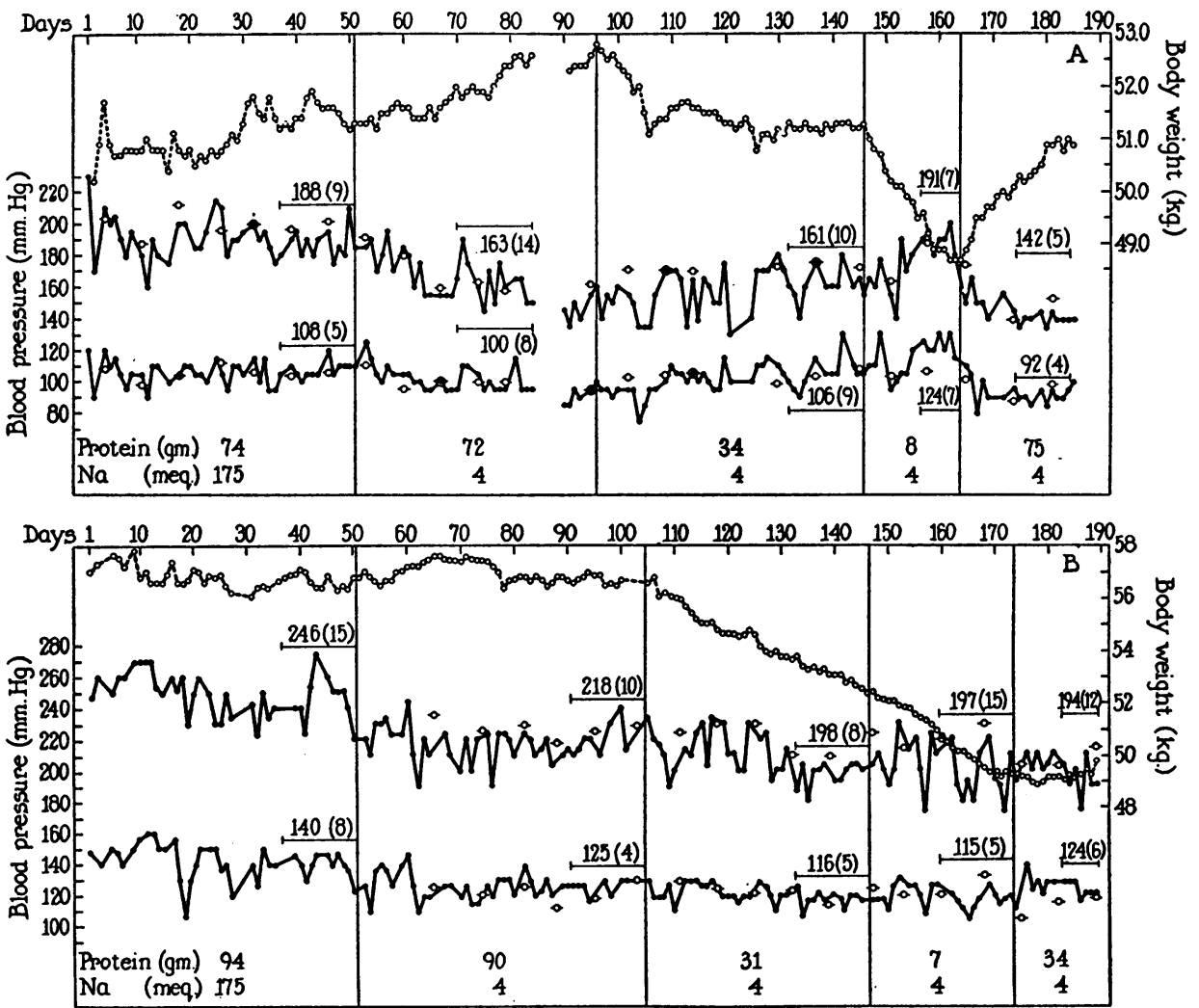

Fig. 1. Daily Values of Morning Weight and Basal Blood Pressures of Patients A AND B

The weight curve (upper line) is referred to the ordinate scale at the right; the two lower curves, giving systolic and diastolic pressures, refer to the scale at the left. The mean and standard deviation of blood pressures are given with horizontal lines that indicate the span of the averaging. Light circles amidst the curves of blood pressure indicate the values that were obtained under the non-basal conditions of service rounds. 
TABLE II

Metabolic data

Blood pressure values are the means and standard deviations of basal pressures over periods of two weeks

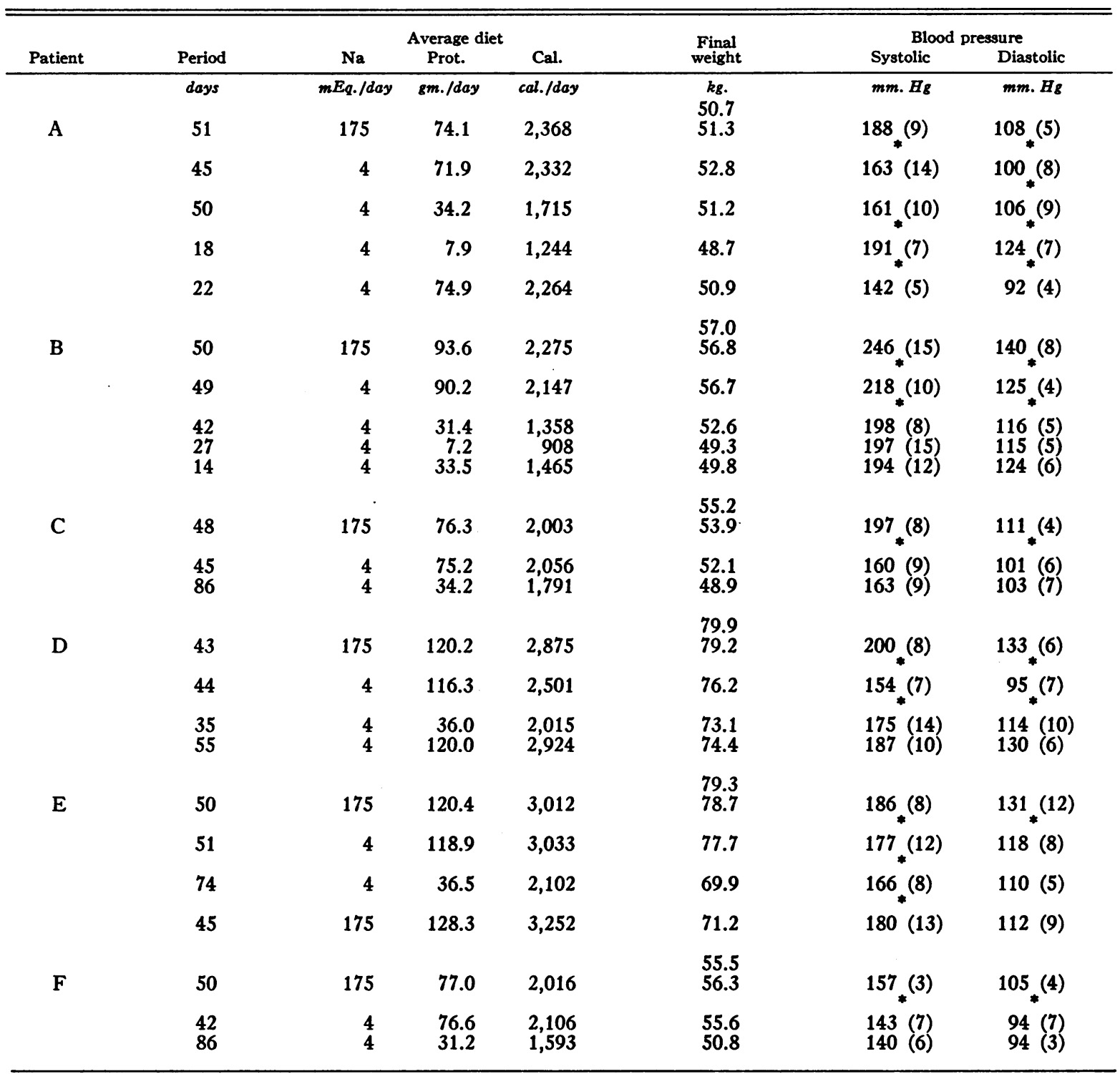

* Asterisk indicates a significant difference between consecutive values.

12 weeks in duration, the supplement of protein was discontinued, so that the patients subsisted on the basal diet alone. Two patients ( $A$ and $B$ ) thereafter were given brief trials of treatment with the diet of minimal protein content ( $0.15 \mathrm{gm}$. protein per $\mathrm{kg}$. day), and then were returned to the basal diet.

As in the previous studies $(1,2)$, the patients were weighed to a precision of $\pm 100 \mathrm{gm}$. each morning after they had voided and before breakfast. The basal blood pressures were determined each morning after the patients had remained quietly in bed for at least one hour. As an additional measure of the blood pressures, readings were made by 3 to 5 physicians during the weekly service rounds. It had been expected that these would reflect the greater emotional stress of the occasion; on the contrary, the average values that were obtained during rounds were not significantly higher than the resting pressures that had been obtained earlier in the morning (Figure 1). An analysis of variance (7) showed that the difference between these two measures of pressure was no greater than would be expected from the variance between the values of resting blood pressure on consecu- 
tive days. This result suggests that the average blood pressures during the moderate stimulation of ward activity were near the basal values.

\section{ANALYSIS OF DATA}

\section{Appetite and weight}

Changes in the appetite and weight of the patients were produced consistently by changes in the ration of protein. With decreases in protein from a high (1.4 to $1.6 \mathrm{gm}$. per $\mathrm{kg}$. day) to an intermediate ( 0.5 to $0.7 \mathrm{gm}$. per $\mathrm{kg}$. day) level or from intermediate to low ( $0.15 \mathrm{gm}$. per $\mathrm{kg}$. day), a reduction in caloric intake soon followed; with increase in protein a greater number of calories were taken (Table II). The relation between these two variables is given by the regression equation, $\mathrm{C}=(1116 \pm 97)+(14.6 \pm 1.2) \mathrm{P}$, where $\mathrm{C}$ and $\mathrm{P}$ are calories per day and gm. protein per day, respectively (Figure 2 ). The most interesting feature of this equation is the magnitude of the slope, $14.6 \mathrm{cal}$. per gm. protein. This is considerably greater than the caloric value of protein alone, 4.1 cal. per gm. protein; therefore a variation in the dietary protein was attended by a proportional variation in the quantity of non-protein constituents. The reason for such a correlated variation is not immediately evident, since each patient was

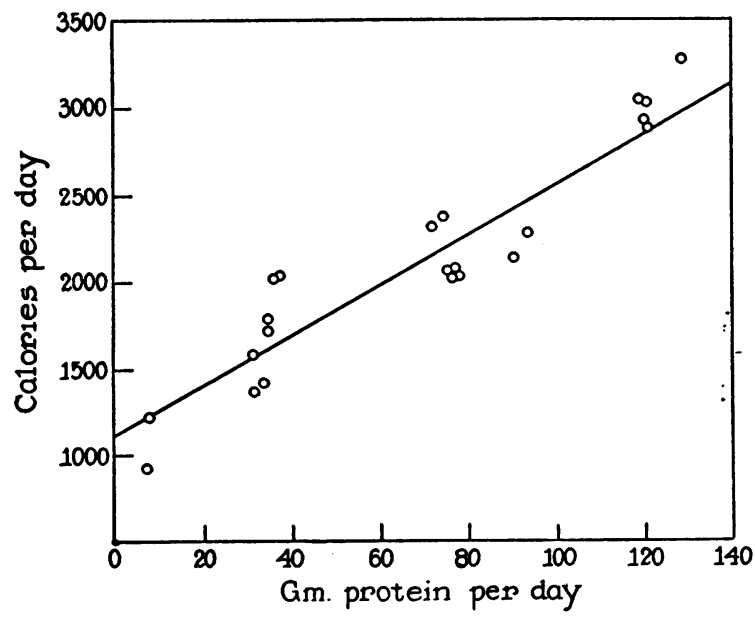

Fig. 2. Relation Between the Self-Determined Intake of Calories and the Prescribed Ration of Protein During the Periods of Metabolic Transition That Followed Changes in the Ration of Protein

The line corresponds to the regression equation, $\mathrm{C}=$ $(1,116 \pm 97)+(14.6 \pm 1.2) P$, where $C$ and $P$ are calories per day and gm. protein per day, respectively. allowed an unlimited intake of low protein foods, and thus remained in control of total caloric level. During the period of adaptation to a new level of dietary protein, therefore, the appetite as measured by this self-determined intake of calories was systematically influenced by the daily ration of protein.

It might be supposed that the increase of caloric intake with increase of dietary protein was merely an expression of the specific dynamic action of proteins. This is far from the case, however, since even the high value of 33 per cent for specific dynamic effect of added protein would imply an added output of heat of only $1.35 \mathrm{cal}$. per gm. protein, less than one-tenth the actual value. Indeed, the changes in body weight prove that the variations in quantity of dietary protein had more profound effects than simple changes in metabolic rate.

It may be seen in Table II that a reduction in dietary protein was followed invariably by a reduction in body weight, and an increase in protein by an increase in weight. These variations in weight were not due merely to changes in hydration; a gain or loss of subcutaneous fat was evident to inspection when the observations were extended over several weeks. Therefore, since a positive caloric balance was required for the weight gain during the periods of high protein feeding and negative balance must have prevailed during the restriction of protein, the feeding of protein must have stimulated a consumption of calories in excess of expenditure, and the restriction of protein must have depressed the consumption below expenditure. The negative caloric balances, shown at intakes of 0.5 to $0.7 \mathrm{gm}$. protein per $\mathrm{kg}$. day, moreover, were not due to inability to attain nitrogen equilibrium at this level; in a previous study (1) it was shown that similar patients, given sufficient time, approached nitrogen balances at even lower levels of consumption.

\section{BLOOD PRESSURE}

It had been observed (2) that patients remained hypertensive during control periods in which the basal diet was supplemented with sodium chloride (10 gm. per day), and responded to omission of the salt with declines in blood pressure. Although these results illustrated the fact that restriction of 

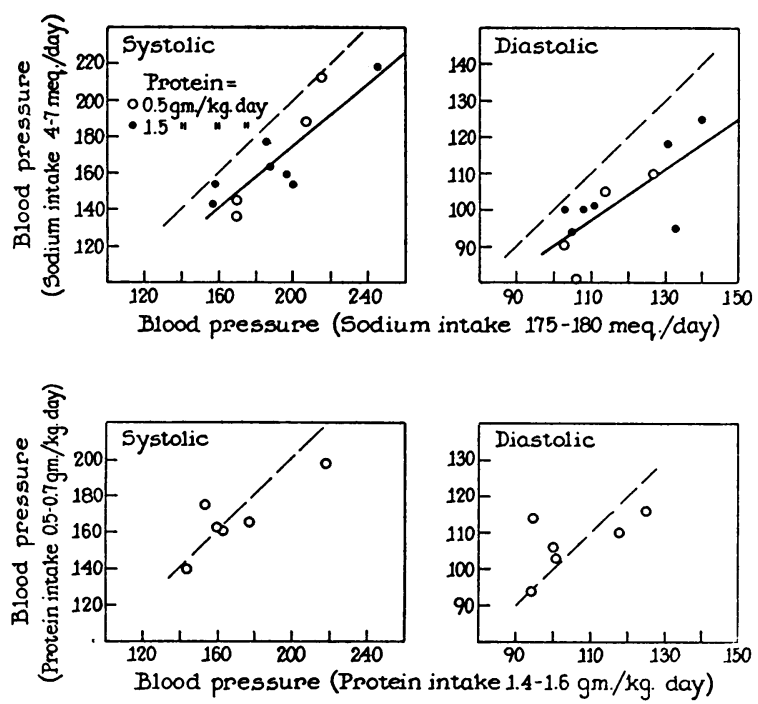

Fig. 3. Correlation of Mean Basal Blood Pressures Before and After Change in a Single Dietary FACTOR

The upper pair of graphs show the response to reduction of dietary sodium; the points shown by open circles refer to patients who experienced the reduction of sodium after a control period in which dietary protein was low, while the solid points refer to comparable patients who received supplementary protein. The dotted lines show the mean positions to be expected if the dietary change were without effect; the solid lines, showing linear regressions, are significantly different. The lower pair of graphs show that change in the level of dietary protein was without effect on the blood pressure of patients who received approximately $4 \mathrm{mEq}$. sodium per day.

sodium is necessary for a therapeutic effect, they did not answer the possibility that the considerable losses in weight and the associated metabolic changes during the control periods may have conditioned the response to a subsequent withdrawal of sodium.

In the present investigation the dietary protein was maintained at a high level (1.4 to $1.6 \mathrm{gm}$. per $\mathrm{kg}$. day) during both the control period and the subsequent period of salt restriction. As a result of the addition of protein to the basal diet, the patients maintained steady weights, or actually gained. Despite the differing effects on body weight, the two regimens produced comparable responses to the restriction of sodium (Figure 3 ).

As a further test of the matter, the intakes of protein were varied while the intake of sodium remained low ( $4 \mathrm{mEq}$. per day). Reduction of dietary protein to an intermediate level ( 0.4 to 0.6 gm. per kg. day) was without consistent effect on the blood pressure (Figure 3), although it caused reductions of body weight (Table II). Extreme reduction of protein ( $0.15 \mathrm{gm}$. per $\mathrm{kg}$. day) was followed by a rise of blood pressure in one patient and no change in the other (Figure 1).

Statistical analysis of these results confirmed the impression that the quantitative reductions of blood pressure were unrelated to the state of protein metabolism within the limits studied. The mean basal pressures after reduction of dietary sodium proved to be simply proportional to the mean pressures of the control period. Expressed as percentage reductions of the control values, the decrements of systolic and diastolic pressures had an identical value, $12 \pm 7.4$ per cent. The high coefficient of variation (60 per cent) is in notable contrast to the uniformity of treatment; presumably it reflects a variable capacity to respond.

\section{DISCUSSION}

\section{Appetite and weight}

These results show that appetite and body weight can be controlled under some conditions by changes in the amount of dietary protein. This effect is to be expected when any essential factor in the diet is reduced enough to limit metabolism; it is just such an action that defines the essential nature of a food. Usually in clinical nutrition, however, the limiting action of essential foods has been seen in the diseases that follow extreme restriction. In the present study a limiting action occurred on what must be considered an adequate diet, since diets even lower in protein suffice for nitrogen balance and maintenance of weight (1). If further proof of adequacy be needed, it can be pointed out that a large number, perhaps a majority, of the people in the world live, work and reproduce on diets that are at least as restricted.

It seems paradoxical that patients should lose weight when changed from one adequate diet to another. Two explanations are possible. The first and conventional one is that time is required for the organism to increase its efficiency, and during this period of adaptation, tissue is lost because of wasteful expenditure. An alternative is that loss of tissue is essential to the adaptation, being in fact a part of the metabolic adjustment. 
The second explanation appears to us more probable. The organism maintains a steady state of composition despite the fact that it is composed of a vast number of substances in ceaseless flux, forming a set of interacting rate processes. Even a slight imbalance of rates would destroy the steady state. Certainly any change in the rate of one process would change the inventory of metabolites that are shared with other rate processes. Following such a change a new steady state might or might not be reached, depending on whether the changes in inventory bring the rates again into balance. In clinical nutrition a failure to reach a new steady state is illustrated by any severe deficiency which causes progressive deterioration and death. Milder limitations, such as were imposed in the present study, lead to a new steady state, but it should be emphasized, only after the necessary changes have been made in the inventory.

This explanation assumes that the dietary supply of an essential food may determine rates, even when the quantity of food is varied in a range above the minimum for a steady state. To some extent, at least, this must be true for all foods that are excreted in an altered form. In particular for protein, work with rats has shown that the quantity of protein in the diet has a marked effect on the quantity and metabolic activity of proteins in the liver, kidney and plasma (8).

The effect of the present diet on appetite may be given two different kinds of explanation. The first is that the diet is monotonous or uninteresting, and so the patients just eat less. Although this seems to be a reasonable statement, it really is not an explanation since it merely restates the result. The second is that the appetite responds to the state of metabolic inventory in such a way that the organism is motivated to eat when the inventory has been depleted and to reject food when items have accumulated. If we assume this, we can trace a sequence of cause and effect in the response to lowered dietary protein. The first effect of lowered dietary supply is a reduction in metabolic activity of proteins and derived metabolites. Because of the imbalance of rates, some of the other metabolites come to be in relative surplus. The appetite, therefore, is depressed and the inventory of the other metabolites is allowed to shrink until a new steady state is reached, a mat- ter of several months in the case of protein restriction (1). Then the appetite returns to a balance with expenditure.

A similar explanation might apply to the high fat and protein reducing diet that was introduced by Pennington (9). In this case the carbohydrate seems to be restricted, and calories in the form of fat, available without limit. Reducing diets of this type, working by an effect on appetite, seem to be more strategically planned than the conventional diets which merely deny calories. Metabolic imbalances probably are inescapable during ing the transitional period of weight loss. Conventional diets with an arbitrary fixation of the whole pattern of intake would seem to offer little scope for compensation. Diets of the sort that control through a limiting factor leave many degrees of freedom to the appetite, and it is reasonable to suppose that the freedom is wisely used. At any rate, it is reported (10) that the usual weakness and hunger of weight reduction are absent on the high fat and protein diet. The present study gave similar results; none of the patients losing weight on the low protein diets admitted hunger or weakness. This, or a similar diet, might have some value in the treatment of obesity.

\section{Blood pressure}

The data support a conclusion of earlier reviewers (11) that the level of dietary protein does not influence the initiation or the maintenance of clinical hypertension. In this respect the results diverge from those reported by Handler and Bernheim in a study of experimental renal hypertension (12). Rats, made hypertensive by constriction of one kidney, became normotensive on rations that provided a normal intake of sodium, but which were restricted either in the quantity of protein or total calories; restriction of sodium, on the other hand, had but little effect on the blood pressure of rats on high protein rations. The discrepancy between the clinical and the experimental results might be due either to the difference in species or to a difference in etiology of the hypertensions.

\section{SUM MARY}

The reduction of blood pressure following restriction of dietary sodium was found to be in- 
dependent of tenfold variations in the ration of dietary protein, and unaffected by prior or subsequent reduction of body weight. The data indicate that restriction of dietary sodium may be expected to reduce the systolic and diastolic blood pressures by $12 \pm 7.4$ per cent.

The ration of protein, under the conditions of this study, was seen to determine the appetite and the body weight of each patient. It might seem odd that patients lost weight when changed from one adequate diet to another, but the result can be explained on the hypothesis that the reduction of body mass is an adaptation to the reduction of dietary protein. The lack of hunger or weakness during the loss of weight indicated that the diet might be of some use in the treatment of obesity.

\section{REFERENCES}

1. Dole, V. P., Dahl, L. K., Cotzias, G. C., Eder, H. A., and Krebs, M. E., Dietary treatment of hypertension. Clinical and metabolic studies of patients on the rice-fruit diet. J. Clin. Invest., 1950, 29, 1189.

2. Dole, V. P., Dahl, L. K., Cotzias, G. C., Dziewiatkowski, D. D., and Harris, C., Dietary treatment of hypertension. II. Sodium depletion as related to the therapeutic effect. J. Clin. Invest., 1951, 30, 584.
3. Goldenberg, M., Snyder, C. H., and Aranow, H., Jr., New test for hypertension due to circulating epjnephrine. J. A. M. A., 1947, 135, 971.

4. Bills, C. E., McDonald, F. G., Niedermeier, W., and Schwartz, M. C., Sodium and potassium in foods and water. Determination by the flame photometer. J. Am. Diet. Assoc., 1949, 25, 304.

5. Sherman, H. C., and Lanford, C. S., The Essentials of Nutrition, New York, Macmillan Co., 1941.

6. Bridges, M. A., and Mattice, M. R., Food and Beverage Analyses, Philadelphia, Lea and Febiger, 1942. $2 \mathrm{~d}$ ed. thoroughly rev.

7. Fisher, R. A., Statistical Methods for Research Workers, 10th Edition, Edinburgh, Oliver and Boyd, 1946.

8. Solomon, G., and Tarver, H., The effect of diet on the rate of loss of labeled amino acid from tissue proteins. J. Biol. Chem., 1952, 195, 447.

9. Pennington, A. W., Obesity in industry. The problem and its solution. Indus. Med., 1949, 18, 259.

10. Woody, E., Eat well and lose weight. Holiday Magazine, 1950, 7, 64.

11. Chapman, C. B., and Gibbons, T. B., The diet and hypertension. A review. Medicine, 1950, 29, 29.

12. Handler, P., and Bernheim, F., Importance of dietary protein, calories and salt in experimental renal hypertension. Am. J. Physiol., 1950, 160, 31.

13. Duncan, G. G., Diseases of Metabolism: Detailed Methods of Diagnosis and Treatment. A text for the practitioner. Philadelphia, W. B. Saunders Co., 1942, p. 938. 